\title{
An Approach to Improve Energy and Cost Performance of a Social Housing Archetype in Cold Climate Region
}

\author{
Yiğit Yılmaz ${ }^{1, *}$, and Burcu Çiğdem Yılmaz ${ }^{1}$ \\ ${ }^{1}$ Bahcesehir University, Faculty of Architecture and Design, Istanbul, Turkey
}

\begin{abstract}
The importance of building energy performance has been substantially increasing in the last decades due to the global warming. Therefore, buildings within the existing stock and the new buildings are encouraged to achieve the energy performance restrictions and efficiency levels. In this context, a social housing archetype (Harct), which is constructed in each climate region of Turkey with a common design approach for temperate climate region, is evaluated as a base case to improve the energy performance for the cold climate region by the optimization of the life cycle cost (LCC). It is, namely, aimed to not only improve the energy performance of the archetype but also to ensure optimal cost efficiency as significant criterion.

It is focused to optimize the façades of the Harct in terms of window width, and optic and thermo-physical properties of the façade with determining the efficient insulation thickness level for exterior walls and efficient glazing types for windows. Firstly, façade design is analysed to find out the minimum and maximum windows' widths to achieve the optimal window sizes. Secondly, optic and thermo-physical properties and cost data of the opaque and transparent façade elements have been designated among the market products in accordance with the current regulations. Energy model of the building has been run by Energy Plus simulation tool, in order to integrate it with GenOpt for optimization. Optimization was performed to carry out efficient frontier cases. The results were evaluated from life cycle cost (LCC) and energy efficiency point of view to highlight the cost optimal point
\end{abstract}

\section{Introduction}

Building stock is one of the major actors on global warming, by consuming approximately $\% 40$ of the total global energy consumption. Therefore, it is precisely essential for decision makers to take the energy efficiency of new and existing buildings into consideration, in order to deal with the global warming issue.

Today, the most significant action addressing the building energy performance in Europe is the Directive of the European Parliament and of the Council [1] on the Energy Performance of Buildings. The objective of [1] is to promote the improvement of the energy performance of buildings by designating minimum energy performance requirements for new and existing buildings. EPBD Recast [2] defines the "cost optimal levels of minimum energy performance requirements" so that those requirements should be set with a view to achieve the cost-optimal balance between the investments involved and the energy costs saved throughout the lifecycle of the building.

In this context, this study aims to achieve cost optimal energy efficient alternatives for a selected multistory social housing archetype, which is constructed by the Housing Development Administration of Turkey
(TOKI) in each climatic region of Turkey with similar approaches. Thereby, the proposed approach focuses on the optimization of building façade's parameters such as the window width, glazing type, and exterior walls' thermal insulation material thickness, in accordance with the energy and cost performances. This study focuses on the cold climate and the cardinal directions are taken into consideration so that the assigned independent variables are applied on the north, south, and east \& west facades, separately.

\section{Methodology}

A social housing archetype (Harct), is designated as the base case for this study. However the archetype was designed as to be constructed in the temperate climate region, it has been also constructed in the cold climate region with the commonly similar features. In order to fix this contradiction, the base case is analysed to determine the independent variables of the façade for optimization of the thermo-physical properties for each cardinal direction according to the regional climate conditions. The value range of the independent variables affecting the façade design are delimitated with respect to the base case design. Moreover, minimum and maximum value of the variables are designated with

\footnotetext{
* Corresponding author: yigit.yilmaz@ arc.bau.edu.tr
} 
utilization of the standards and the local market products. Energy model of the base case has been constituted by Energy Plus simulation tool to integrate with GenOpt for the optimization. The variable parameters are optimized for South, North, and East \& West facades in terms of the primary energy use and the life cycle cost. Finally, results are evaluated as optimum cases and efficient ranges from energy and cost efficiency point of view as a decision guide for decision makers.

\subsection{Determination of the archetype and the climate region}

Since social housing has increasingly been constructed in all around Turkey by the Housing Development Administration of Turkey, a commonly used archetype was designated as the base case for this study [3].

There are 4 flats in each floor of the archetype, consisting of 11 storeys with $3520 \mathrm{~m}^{2}$ total conditioned area $\left(80 \mathrm{~m}^{2}\right.$ per apartment unit) and $605 \mathrm{~m}^{2}$ unconditioned area (circulation, core, etc.). Typical floor plan is shown in Figure 1.

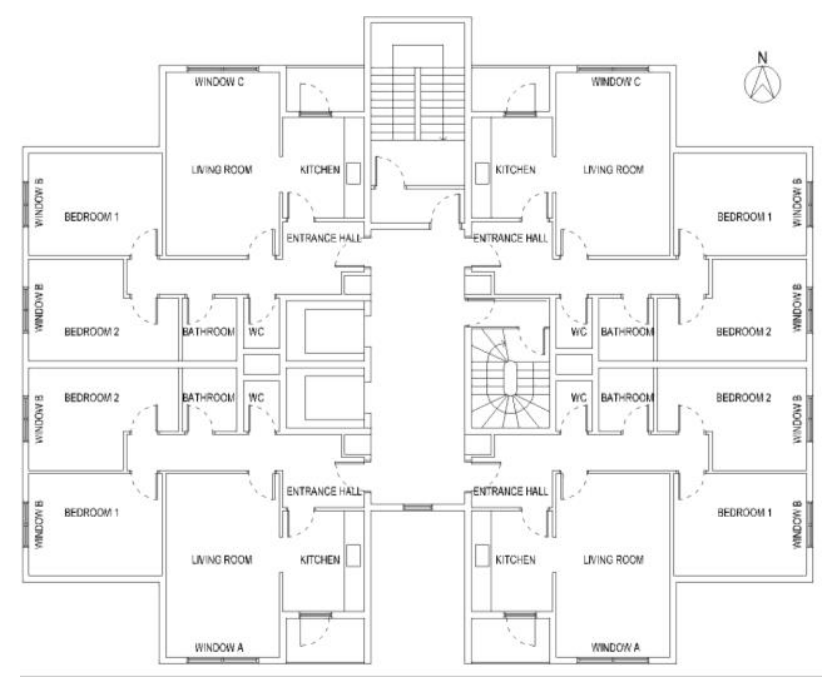

Fig. 1. Typical Floor Plan of the Harct.

Optic and thermo-physical features of the base case archetype's façade are assigned according to the reference values reported in "TS 825 Turkish Standard for Thermal Insulation in Buildings" [4]. Whereby, in the base case, windows have $1.60 \mathrm{~W} / \mathrm{m}^{2} \mathrm{~K}$ thermal transmittance, 0.70 solar heat gain coefficient (SHGC), and 0.80 visible transmittance. Additionally, exterior walls have $0.396 \mathrm{~W} / \mathrm{m}^{2} \mathrm{~K}$ thermal transmittance. Details of the window, glazing and wall construction is given in Figure 2.

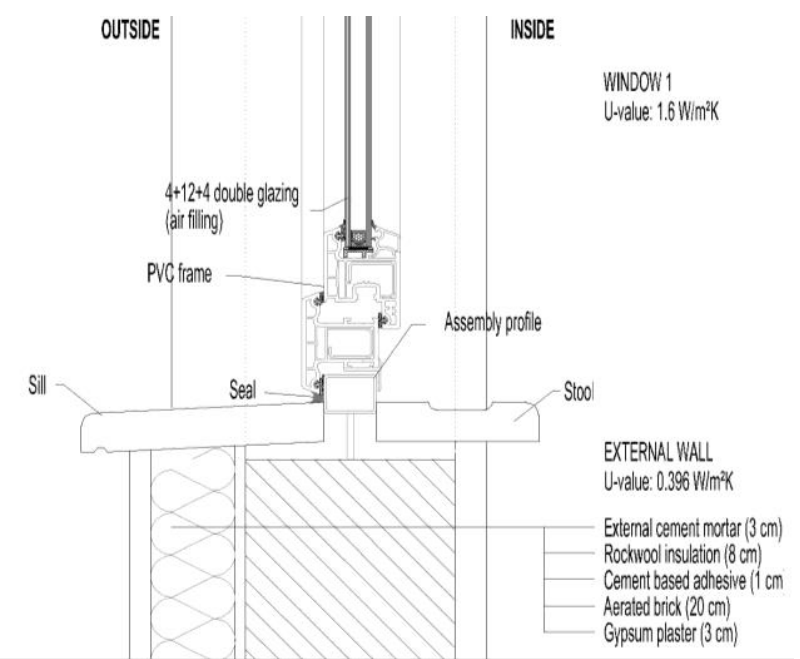

Fig. 2. Exterior Wall Detail of the Harct.

In Turkey, social housing archetypes are mostly designed as to be constructed in the most broaden climate region of Turkey, which corresponds to the temperate climate region. Whereas, the similar social housing designs are constructed in each climate region with just adjusting the U-value of the envelope components in accordance with TS825 [4] reference values. In order to reveal the contradictions occurring in other climates than the temperate climate, cold climate region is selected and Erzurum city and its typical meteorological year data [5] were involved to the calculation.

The cold climate, which is represented in this study with the Erzurum city, has the outdoor air temperatures varying between $-20{ }^{\circ} \mathrm{C}$ and $30{ }^{\circ} \mathrm{C}$ during the year. Monthly average direct solar radiation varies between 60 $\mathrm{W} / \mathrm{m}^{2}$ (winter) and $210 \mathrm{~W} / \mathrm{m}^{2}$ (summer peak).

\subsection{Designation of variable parameters}

Façade system of a building, with its optic and thermophysical behaviour, is one of the dominant factors regarding energy demand of a building. In this study, façade' parameters are targeted to be improved in terms of energy and cost efficiency.

Façade components of the base case archetype are consisting of windows as the transparent component and exterior walls as the opaque component. Windows are crucial on both heating, cooling and lighting energy demand of the building with its thermal and the lighting transmittance, the solar heat gain coefficient and the air tightness. Therefore, glazing type and the window width are involved to the optimization with determined range of values to differentiate the features of the windows.

In addition, since the exterior walls mostly effect the heat transfer amount through the envelope and thermal performance of the building, insulation thickness is determined as the independent variable of the opaque component to be optimized within the determined range.

In order to set the range of values for the selected parameters, local conditions (products within local market for windows and thermal insulation level regulations for exterior walls) are analysed to obtain the 
available options and limitations. Frame of the windows are fixed to PVC material within the commonly used three options (PVC, aluminium, wood). There are four mostly used alternatives for glazing system, which are also ensuring the minimum U-value given by [4], as reported in Table 1. Moreover, insulation thickness of the exterior walls was assigned between $8 \mathrm{~cm}$ and $16 \mathrm{~cm}$, in accordance with the thermal insulation regulations and local construction opportunities for minimum and maximum values.

Table 1. Window Types.

\begin{tabular}{|c|c|c|c|}
\hline Name & $\begin{array}{c}\text { Visible } \\
\text { Transmittance } \\
(\%)\end{array}$ & $\begin{array}{c}\text { Solar Heat } \\
\text { Gain } \\
\text { Coefficient }\end{array}$ & $\begin{array}{c}\text { U-value } \\
\left(\mathrm{W} / \mathrm{m}^{2}\right. \\
\mathrm{K})\end{array}$ \\
\hline Window 1 & 79 & 0.64 & 1.6 \\
\hline Window 2 & 79 & 0.64 & 1.3 \\
\hline Window 3 & 71 & 0.51 & 1.1 \\
\hline Window 4 & 71 & 0.59 & 0.8 \\
\hline
\end{tabular}

\subsection{Base case analysis}

Base case was analysed to constitute framework for the variables in order to set them compatible with the base case design. The main decisions of this step are reported as below;

- As shown in the floor plan in Figure 1, each façade has a symmetry from the center, whereby there are symmetrical windows on each part. In order to keep the design principles (such as symmetry, repetition etc.) of base case in optimization, symmetrical and identical windows for each façade are clustered as window sets such as Window A, B and C to keep them identical and symmetrical in the optimization as well.

- The parapet height of the windows are fixed to $90 \mathrm{~cm}$ in the optimization, as the interior surfaces of the exterior walls serve for the baseboard heating in the base case. Therefore the height of the windows were also fixed as $150 \mathrm{~cm}$, and not involved to the optimization.

- According to the author's experience in architecture, the minimum width for windows was assumed as 100 $\mathrm{cm}$ for each room in the optimization.

- Figure 1 shows that each window is located at the center of the room's exterior wall. In order to keep the central location of the windows, each window width is varied from both sides equally.

- Each façade is exposed to different climatic conditions according to the direction. Therefore, the variables of each façade are separately involved into the optimization except east and west façade. In order to decrease the number of scenarios in the optimization, variables of west and east facades are optimized together due to the symmetry and similar outdoor environmental factors.
GenOpt optimization tool has been chosen to be integrated with Energy Plus so as to optimize the variables of the building façade such as window width, exterior wall insulation thickness, window type for each façade from the life cycle cost point of view. GenOpt optimization tool introduces some multidimensional algorithms to find out the minimum cost function for either discrete or continuous variables. In this study, all the independent variables have discrete values, therefore, two of the multidimensional algorithms are applicable to optimize discrete values. Moreover, Hybrid Generalized Pattern Search Algorithm with Particle Swarm Optimization Algorithm (GPSPSOCCHJ), is one of the two options, was assessed as the best along nine optimization algorithms run with EnergyPlus [6]. This algorithm was determined to carry out a global minimum through PSO algorithm and a local minimum through HJ algorithm.

In the energy calculation part of the optimization, primary energy use of the scenarios were calculated through Energy Plus simulation tool, on the hourly basis, with six time steps per hour. Conduction transfer function algorithm was selected for the heat balance calculations, with TARP algorithm for inside and DOE-2 algorithm for outside surface convection calculations.

This study takes life cycle cost as the subject to be optimized so as to reach the cost optimal point and the cost optimal energy efficient scenarios. In order to conduct the cost calculation, Global Cost Method $\left(C G_{m}(T)\right)$, which is introduced in EN 15459 [7], is modified to obtain sum of investment $\operatorname{costs}\left(C \mathrm{CO}_{i n v}\right)$, annual energy costs $\left(\mathrm{CO}_{e n}\right)$, and annual costs $\left(\mathrm{CO}_{a}\right)$ during the lifespan as the today's values by converting them with the discount rate $\left(D_{f}\right)$ and the calculated development rate $\left(R A T_{d e v}\right)$ as reported in Equation 1. Annual price escalation rates on energy costs are involved into the LCC calculation to obtain accurate results for 30 years life span.

$$
\begin{aligned}
& C G_{m}(T)=C O_{i n v}+\sum j\left[T C \sum _ { i = 1 } \left(C O_{e n(i)}(j) \times\right.\right. \\
& \left.\left.\left(1+R A T_{d e v}(i)(j)\right)+C O_{a(i)}(j)\right) \times D_{f(i)}\right]
\end{aligned}
$$

The optimization tool optimizes the symmetrical two façades (east and west) and south and north façades separately in terms of thermal insulation thickness, window width and glazing type to improve the energy and cost performance of each façade. Finally, widths of three window sets (window $\mathrm{A}, \mathrm{B}$, and $\mathrm{C}$ ), insulation thicknesses and glazing types of three façades were involved in the optimization as the parameters with different ranges and values.

\section{Results}

The optimization has been conducted with 2805 simulations in 35 generations. In each generation, results of simulations were determinative to select the new value for the variables in order to obtain the global minimum for objective function as the cost optimal scenario. LCC calculation of the scenarios has been done for 30 years life span with the result calculated between 54.60 and $60.05 € / \mathrm{m}^{2}$. On the other hand, energy use of

\subsection{Optimization}


the scenarios has been calculated from 64.12 to 81.75 $\mathrm{kWh} / \mathrm{m}^{2} \mathrm{a}$. The results of the base case, $81.75 \mathrm{kWh} / \mathrm{m}^{2} \mathrm{a}$ for primary energy use and $55.59 € / \mathrm{m}^{2}$ for LCC, were selected as the threshold values for energy and cost efficiency whereas the cost optimal level has 74 $\mathrm{kWh} / \mathrm{m}^{2}$ a primary energy use and $54.60 € / \mathrm{m}^{2} \mathrm{LCC}$. The distribution of the scenarios indicates that number of scenarios are substantially increasing around the cost optimal point in Figure 3, which is proving that optimization algorithm has been worked as targeted to find out the cost optimal case.

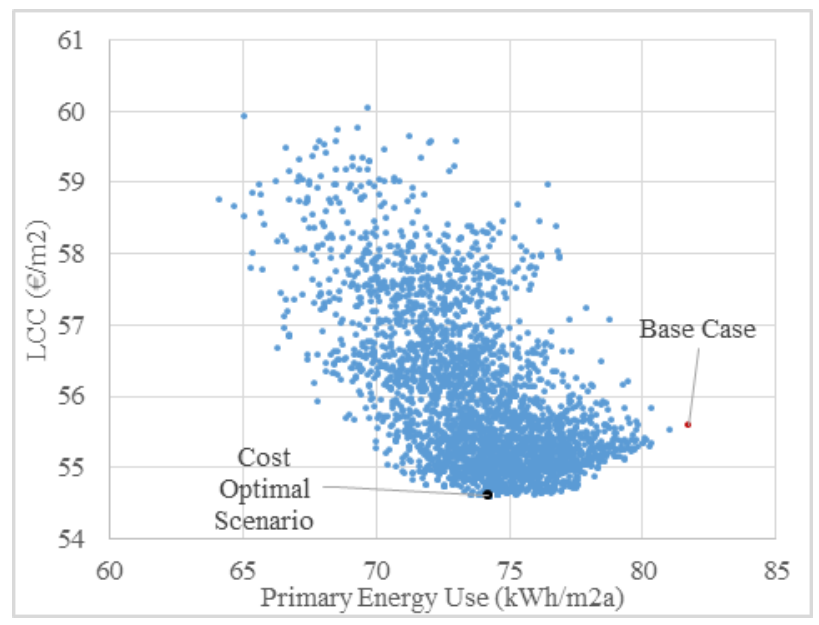

Fig. 3. Primary Energy Use and LLC of the Scenarios.

According to the results, cost optimal level provides $9.5 \%$ energy efficiency than the current requirement level with only an increase of $1.8 \%$ LCC increase due to the increased investment costs.

The façade configuration of cost optimal case emphasises, as reported in Figure 4, that while the width of windows (W2) on the South and East \& West facades are increasing to 270 and $170 \mathrm{~cm}$ respectively, the width of windows (W4) on the North façade are decreasing to $190 \mathrm{~cm}$ in accordance with the climate. Moreover, the insulation thickness of the façade for each direction, as shown in Figure 4, seems reasonable as $11 \mathrm{~cm}$ for the North, $8 \mathrm{~cm}$ for the South and $10 \mathrm{~cm}$ for the East \& West.

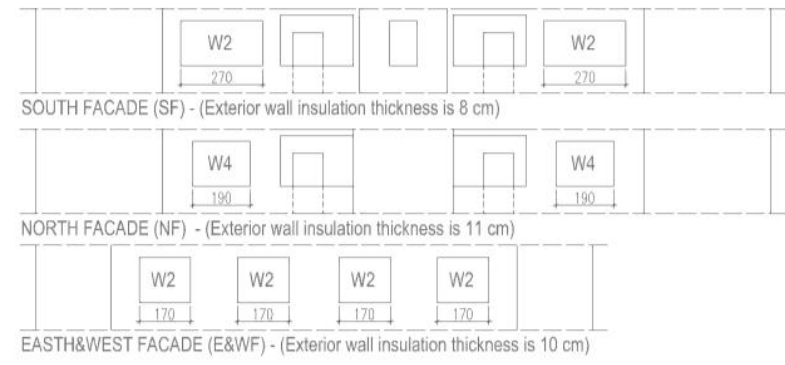

Fig. 4. Cost optimal case's façade configuration.

\section{Conclusion}

A typical social housing project has been studied by the proposed approach to achieve the energy efficient cost optimal levels by optimizing the thermo-physical properties of each façade. In this context, it is observed that the cost optimal scenario has larger windows on South and East \& West facades as W2 and smaller in North façade as W4 compared to the base case. It shows significance of the façade design in accordance with exposed direction and local climatic conditions. Moreover, although the base case has lowest thermal transmittance for each façade within all scenarios, its LCC occupies at around low quarter of the LCC range in Figure 3. It namely indicates the necessity of the cost efficient approach on energy efficiency studies as also referred by EPBD 2010.

The proposed approach emphasizes that it is essential to differentiate the façade design of the typical projects by optimizing the thermo-physical properties of each façade according to local climatic condition and direction so as to accomplish energy efficient cost optimality.

In further studies, author aims to achieve the nearly zero energy building levels and practices for optimized scenarios by also integration of renewable energy systems.

\section{References}

1. Directive 2002/91/EC of the European Parliament and of the Council of 16 December 2002 on the Energy Performance of Buildings. Available at https://eur-lex.europa.eu/legalcontent/EN/TXT/PDF/?uri=CELEX:32002L0091\&f rom=EN. Accessed 19 Oct 2018.

2. Directive 2010/31/EU of the European Parliament and the Council of 19 May 2010 on the Energy Performance of Buildings (recast). Available at https://eur-lex.europa.eu/legal-

content/EN/TXT/PDF/?uri=CELEX:32010L0031\&f rom=EN. Accessed 19 Sep 2018.

3. TOKI Archetype http://www.toki.gov.tr/AppResources/UserFiles/file s/Satis/Ankara/Turkuaz/planlar/B2-KAT.jpg Accessed 11 Mar 2018.

4. TS 825 Standard for Thermal Insulation in Buildings, May 2008, Turkey.

5. TUR_EM_Erzurum.170960_TMYx.2003-2017 weather file. http://climate.onebuilding.org/WMO_Region_6_Eur ope/TUR_Turkey/index.html\#IDEM_ErzurumAccessed 03 Oct 2018.

6. Wetter, M., Wright, J. (2004). A comparison of deterministic and probabilistic optimization algorithms for non-smooth simulation-based optimization. Building and Environment, 39-8, 989999. doi: 10.1016/j.buildenv.2004.01.022

7. EN 15459:2007, CEN [European Committee for Standardization]. Energy performance of buildings Economic evaluation procedure for energy systems in buildings, Brussels: CEN; 2007. 